\title{
Emergency Splenectomy in a Patient with Splenic Marginal Zone Lymphoma, Acute Portal Vein Thrombosis, and Chronic Viral Hepatitis B
}

\author{
Radmila Karpova (D) \\ Andrey Gorbunov (1D' \\ Marina Mnatsakanyan (D) ${ }^{2}$ \\ Aleksandr Pogromov $\mathbb{D}^{2}$ \\ Irina Sokolova $\mathbb{D D}^{2}$ \\ Yuliya Shumskaya (iD ${ }^{2}$ \\ Ksenia Russkova (D) \\ Kirill Chernousov (D) \\ Daria Momatyuk (iD) ${ }^{3}$

\begin{abstract}
'Department of Faculty Surgery No.I, University Clinical Hospital No.I, I.M. Sechenov First Moscow State Medical University (Sechenov University), Moscow, Russia; ${ }^{2}$ Department of Hospital Therapy No.I, University Clinical Hospital No.I, I.M. Sechenov First Moscow State Medical University (Sechenov University), Moscow, Russia; ${ }^{3}$ Institute of Clinical Medicine, I.M. Sechenov First Moscow State Medical University (Sechenov University), Moscow, Russia
\end{abstract}

Correspondence: Ksenia Russkova Institute of Clinical Medicine, I.M. Sechenov First Moscow State Medical University (Sechenov University), 8-2 Trubetskaya st, Moscow, I 1999I, Russia Tel +79050164054

Email russkova.ksy@gmail.com

\begin{abstract}
Splenic marginal zone lymphoma (SMZL) is a type of non-Hodgkin's lymphoma $(\mathrm{NL})$ that occurs in 2 out of 100 cases and is more common in women aged $>60$ years. A sluggish, asymptomatic course of the disease does not exclude transformation into a malignant form that occurs in $25 \%$ of patients with SMZL. Another equally important sign of an NL is thrombosis that occurs in $3.6 \%$ to $17.1 \%$ of the cases. In this report, we present a case of emergency splenectomy in a patient owing to difficulties in the diagnosis of SMZL, rapid onset of acute portal vein thrombosis, and the fulminant enlargement of the spleen accompanied by an increased risk of its rupture. Chronic hepatitis B was likely the trigger for transformation of the disease to an aggressive course. Portal vein thrombosis and the aggressive course of SMZL with rapid enlargement of the spleen and threat of its rupture in the background of viral hepatitis B required emergency splenectomy followed by anticoagulant, antiviral, and antitumor therapy.
\end{abstract}

Keywords: splenic marginal zone lymphoma, SMZL, portal vein thrombosis, emergency splenectomy, chronic viral hepatitis B

\section{Introduction}

Splenic marginal zone lymphoma (SMZL) is a type of non-Hodgkin's lymphoma (NL) that occurs in 2 out of 100 cases and is more common in women aged $>60$ years. ${ }^{1}$ A sluggish, asymptomatic course of the disease does not exclude transformation into a malignant form that occurs in $25 \%$ of patients with SMZL. ${ }^{2}$

Most frequently, SMZL develops in the background of viral hepatitis $\mathrm{C}$, which causes antigenic stimulation of B-cells and triggers mutations in immunoglobulin coding genes. ${ }^{3}$ A similar pathogenesis has been described in studies on SMZL among patients with viral hepatitis $\mathrm{B}^{4}$

Another equally important sign of an NL is thrombosis that occurs in $3.6 \%$ to $17.1 \%$ of the cases. According to these cases, arguments for the desirability of anticoagulant administration remain controversial and require additional research. ${ }^{5-}$ ${ }^{7}$ The literature describes a clinical case report about the onset of iliac vein thrombosis in a patient with SMZL that had been caused by the antiphospholipid activity of monoclonal $\operatorname{IgM}^{8}$ Administration of anticoagulants in this case led to recanalization of the iliac vein.

In this report, we present a case of emergency splenectomy in a patient owing to difficulties in the diagnosis of SMZL, rapid onset of acute portal vein thrombosis, 
and the fulminant enlargement of the spleen accompanied by an increased risk of its rupture.

\section{Case Report}

A 57-year-old female was admitted to the Clinical Hospital No. 1 of Sechenov University on August 16, 2019 because of weakness, recurrent extended abdominal pain, and an increase in body temperature up to $39^{\circ} \mathrm{C}$. The patient had a medical history of untreated viral hepatitis B (inactive carriage) for over 20 years. The first symptoms presented 2 weeks before admission.

Physical examination of the patient revealed pallor of the skin and moist tongue that was furred with a white coating. The lungs were clear to auscultation bilaterally. The heart sounds were muffled at auscultation with a pulse rate of 72 beats/min. The abdomen was soft and nontender, and the liver size was within normal limits. Splenomegaly was found during percussive estimation of the spleen, with dimensions of $13 \times 10 \mathrm{~cm}$. The spleen protruded from the costal arch within $7 \mathrm{~cm}$, the surface of which was elastic and smooth during palpation.

The patient had no family history of cancer, addiction to alcohol, tobacco, or drugs, or known allergies. Signed consent of the patient for the examination and treatment was obtained.

Complete blood count and metabolic panel included: hemoglobin $98 \mathrm{~g} / \mathrm{L}$, red blood cells $3.95 \times 10^{12}$ cells/L, platelet count $110 \times 10^{9}$ cells $/ \mathrm{L}$, white blood cells $2.8 \times 10^{9}$ cells $/ \mathrm{L}$, ferritin $1080 \mathrm{ng} / \mathrm{mL}$, ferrum $5 \mathrm{mmol} / \mathrm{L}$, total protein $71.6 \mathrm{~g} /$ $\mathrm{L}$, albumin $37.1 \mathrm{~g} / \mathrm{L}$, total bilirubin $13.2 \mathrm{mmol} / \mathrm{L}$, AST 27 IU/L, ALT $40 \mathrm{IU} / \mathrm{L}$, and alkaline phosphatase $269 \mathrm{IU} / \mathrm{L}$.

Coagulogram data included: plasma fibrinogen $5.51 \mathrm{~g} /$ $\mathrm{L}$, prothrombin index (PTI), 74\%, international normalised ratio (INR) 1.17, and partial thromboplastin time (PTT) 0.97 .

Ultrasonography and computed tomography (CT) of the abdominal organs revealed normal size of the liver and intrahepatic bile ducts. The hepatic parenchyma included multiple calcifications of up to $1 \mathrm{~cm}$ in diameter. The portal vein was $11 \mathrm{~mm}$ in diameter, and its linear blood flow velocity was estimated to be $12 \mathrm{~cm} / \mathrm{s}$. The gallbladder was normal. The spleen was enlarged to $135 \mathrm{~mm} \times 75 \mathrm{~mm} \times 155 \mathrm{~mm}$. Its parenchyma included calcifications up to $0.5 \mathrm{~cm}$ in diameter and active specific tissue. The splenic vein diameter was $11 \mathrm{~mm}$, and its linear blood flow velocity was $12 \mathrm{~cm} / \mathrm{s}$. No free liquids were detected in the abdominal cavity. These observations were indicative of splenomegaly, portal hypertension, and no lymphadenopathy.
During EGD, atrophic gastritis of the antrum was observed. Esophageal or gastric varicose veins were not detected. Liver fibrosis was estimated by FibroScan indicating 1st degree fibrosis (stage F1 on the METAVIR scale). The serological study showed the reactivation of chronic hepatitis (titer of HBsAg 6819 IU/mL DNA HBV $[+]$ ); therefore, antiviral therapy, including entecavir $1 \mathrm{mg}$ $\times 1$ time per day, was prescribed.

The etiology of splenomegaly remained unclear. Symptoms, fever, laboratory changes (pancytopenia), and enlargement of the spleen during reactivation of viral replication indicated the presence of a lymphoproliferative disease. Based on this fact, during the follow-up examination, bone marrow biopsy was performed. Cytological examination revealed insignificant lymphoproliferation. There were no pathological changes or lymphocytosis shown in the myelogram. There were no mutations in the JAK2 V617F, MPL 515, and 12ex genes detected by polymerase chain reaction assays.

Antibodies to platelet levels were $260 \%$ (reference range up to 200 ), soluble glycocalicin $70 \%$, immunochemical examination of blood and urine demonstrated decreased IgM concentration up to the low end of the normal range, and inflammatory dysproteinemia was found.

On August 22, 2019, the patient's condition significantly deteriorated due to the onset of acute pain in the abdomen, weakness, and an increase in body temperature up to $38.5^{\circ} \mathrm{C}$. The patient was urgently transferred to the Surgery Department.

On physical examination, the patient's condition was found to be severe, accompanied by skin dryness and a coated tongue. Vesicular respiration was defined throughout the lung fields, and no wheezing was detected. The respiratory rate was 20 breaths $/ \mathrm{min}$. Heart sounds were rhythmic with a pulse rate of 122 beats/min and blood pressure of 110/75 $\mathrm{mmHg}$. The abdomen was distended and painful on palpation. There was muscle tension over the entire surface of the abdominal cavity. The patient had no stool, passage of flatus was normal. The entire left half of the abdominal cavity was occupied by the spleen, which was painful and found to have solid consistency during palpation. The spleen had increased in size by $2 \mathrm{~cm}$ in 3 $\mathrm{h}$ during dynamic monitoring. Ultrasonography and $\mathrm{CT}$ of the abdominal organs revealed that the portal vein was $16 \mathrm{~mm}$ in diameter and contained an occlusive thrombus. The dimensions of the spleen were $260 \times 111 \mathrm{~cm}$. The splenic vein diameter was $18 \mathrm{~mm}$, and its linear blood flow velocity was $3 \mathrm{~cm} / \mathrm{s}$. Due to the threat of rupture of the spleen due to acute thrombosis of the portal vein, an emergency splenectomy 
was performed. The removed spleen was approximately $380 \times 210 \times 170 \mathrm{~mm}$ in size (Figure 1). Histological and immunohistochemical examination of the operating material enabled the identification of splenic marginal zone lymphoma.

The postoperative period was uneventful, lab-based indicators normalized, and the patient's condition improved. The patient was prescribed antitumor therapy (rituximab $375 \mathrm{mg}$ / $\mathrm{m}^{2}$ of body surface once a week for 4 weeks) and anticoagulant therapy (rivaroxaban $20 \mathrm{mg}$ once a day for 6 months). The patient was discharged on the 8th day after surgery. Blood test indicators were as follows: RDW, $16.9 \%$; neutrophils, 63.7\%; and platelet count, $99 \times 10^{9} / \mathrm{L}$. During anticoagulant medication, thrombocytopenia and hypocoagulation persisted. Ultrasonography and CT of the abdominal organs confirmed that there were no free liquids in the abdominal cavity, portal vein diameter was estimated at $18 \mathrm{~mm}$, and partial recanalization with parietal thrombi was determined.

\section{Discussion}

A long-term and asymptomatic clinical course of SMZL is an indication for dynamic observation every 3-6 months. ${ }^{1}$ The

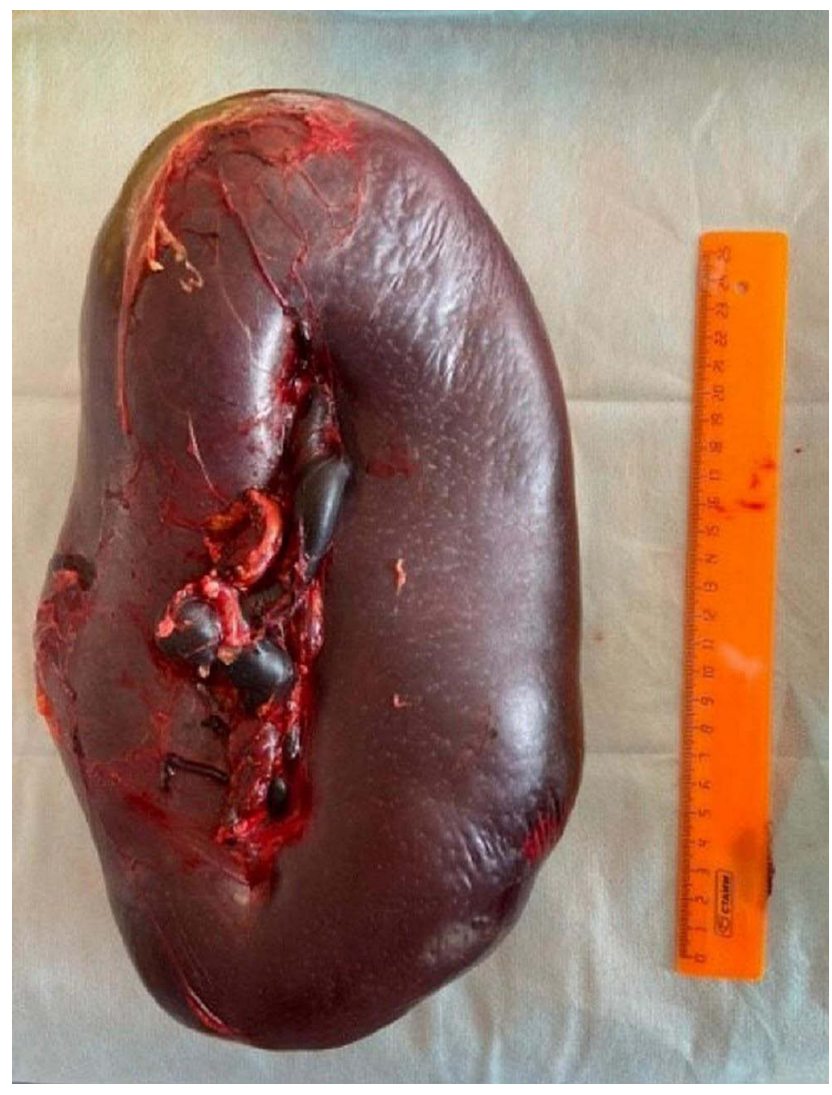

Figure I Removed spleen with thin capsule showing threat of rupture. combination of this type of lymphoma with viral hepatitis B $\left(\mathrm{HBs}^{+}\right)$requires antiviral therapy to treat lymphoma. ${ }^{9}$ Absence of antiviral therapy leads to mutations and errors in the DNA repair pathway with increased synthesis of pathological immunoglobulins as well as stimulation of lymphogenesis. ${ }^{10,11}$ As a result, the benign course of SMZL is transformed into an aggressive form with a mortality rate of $10 \%-20 \%$. ${ }^{11}$ The risk of thrombotic complications is $9.8 \%$ among patients with an aggressive form of the disease that requires anticoagulant therapy. ${ }^{12}$

Malignant transformation of SMZL is a strict indication for splenectomy, which enables the establishment of a diagnosis and prescription of appropriate therapy. The survival rate after splenectomy is $50 \%-80 \%{ }^{1,13}$ However, splenectomy is not always effective in SMZL treatment, and most patients require chemotherapy. ${ }^{1}$

In the present clinical case, accurate diagnosis could not be made initially owing to difficulties during the examination. The disease was long-term and asymptomatic. Chronic hepatitis B was likely the trigger for transformation of the disease into an aggressive course and the development of acute thrombosis, and fulminant enlargement of the spleen accompanied by an increased risk of its rupture required an emergency splenectomy.

After splenectomy, patients with SMZL are traditionally treated with antitumor chemotherapy (rituximab) and antiviral therapy for viral liver damage (hepatitis B or C). Antiviral therapy is added to the treatment for 1 year because the virus can be reactivated due to the effects of chemotherapy drugs and tumor-associated immunodeficiency. ${ }^{1,10}$

In the present case, treatment included antiviral (entecavir $1 \mathrm{mg}$ once a day), antitumor (rituximab $375 \mathrm{mg} / \mathrm{m}^{2}$ of patient's body surface once a week for 4 weeks), and anticoagulant therapy (rivaroxaban $20 \mathrm{mg}$ once a day for 6 months), which stabilized the patient's condition.

\section{Conclusion}

Portal vein thrombosis and the aggressive course of SMZL with rapid enlargement of the spleen with the threat of its rupture in the background of viral hepatitis B requires emergency splenectomy followed by anticoagulant, antiviral, and antitumor therapy.

\section{Consent}

Written informed consent was provided by the patient to have the case details and any accompanying images published. The Institutional consilium of the Clinical Hospital 
No. 1 of Sechenov University gave approval for this case report.

\section{Author Contributions}

All authors made an equal, significant contribution to the work reported, whether that is in the conception, study design, execution, acquisition of data, analysis and interpretation, or in all these areas; took part in drafting, revising or critically reviewing the article; gave final approval of the version to be published; have agreed on the journal to which the article has been submitted; and agree to be accountable for all aspects of the work.

\section{Disclosure}

The authors report no conflicts of interest in this work. This research did not receive any specific grant from funding agencies in the public, commercial, or not-for-profit sectors.

\section{References}

1. Zucca E, Arcaini L, Buske C, et al. Marginal zone lymphomas: ESMO Clinical Practice Guidelines for diagnosis, treatment and follow-up. Ann Oncol. 2020;31(1):17-29. doi:10.1016/j.annonc.2019.10.010

2. Arcaini L, Rossi D, Paulli M. Splenic marginal zone lymphoma: from genetics to management. Blood. 2016;127(17):2072-2081. doi:10.1182/blood-2015-11-624312

3. Xiong W, Lv R, Li H, et al. Prevalence of hepatitis B and hepatitis $\mathrm{C}$ viral infections in various subtypes of B-cell non-Hodgkin lymphoma: confirmation of the association with splenic marginal zone lymphoma. Blood Cancer J. 2017;7(3):e548. doi:10.1038/bcj.2017.28

4. Ulcickas Yood M, Quesenberry CP, Guo D, et al. Incidence of nonHodgkin's lymphoma among individuals with chronic hepatitis B virus infection. Hepatology. 2007;46(1):107-112. doi:10.1002/hep.21642
5. Mahajan A, Wun T, Chew H, White RH. Lymphoma and venous thromboembolism: influence on mortality. Thromb Res. 2014;133 (SUPPL. 2):S23-S28. doi:10.1016/S0049-3848(14)50004-7

6. Gangaraju R, Chen Y, Hageman L, et al. Risk of venous thromboembolism in patients with non-Hodgkin lymphoma surviving blood or marrow transplantation. Cancer. 2019;125(24):4498-4508. doi: $10.1002 /$ cncr.32488

7. Fedorova AS, Dmitriev VV, Lipay N, Markovets AF, Begun I, Dmitriev E. Venous thrombosis in children, adolescents and young adults with lymphomas: incidence, characteristics, risk factors and prognostic value. Oncogematologiya. 2018;13(2):9-20. doi:10.17650/1818-8346-2018-13-2-9-20

8. Martin SE, Abel RF. Splenic marginal zone lymphoma, iliac vein thrombosis, and monoclonal immunoglobulin Mк antiphospholipid antibody with Annexin A5 interaction [16]. Leuk Lymphoma. 2006;47(9):1994-1996. doi:10.1080/10428190600731972

9. Yi S, Yan Y, Xiong W, et al. Distinct clinical characteristics draw a new prognostic model for splenic marginal zone lymphoma in HBV high prevalent region. Oncotarget. 2017;8(58):98757-98770. doi:10.18632/oncotarget.21931

10. Dalia S, Suleiman Y, Croy DW, Sokol L. Association of lymphomagenesis and the reactivation of hepatitis B virus in non-hodgkin lymphoma. Cancer Control. 2015;22(3):360-365. doi:10.1177/ 107327481502200315

11. Sehn LH. Introduction to a review series: the paradox of indolent B-cell lymphoma. Blood. 2016;127(17):2045-2046. doi:10.1182/ blood-2016-03-692442

12. Yıldız A, Albayrak M, Pala Ç, et al. The incidence and risk factors of thrombosis and the need for thromboprophylaxis in lymphoma and leukemia patients: a 9-year single-center experience. J Oncol Pharm Pract. 2020;26(2):386-396. doi:10.1177/1078155219851540

13. Lenglet J, Traullé C, Mounier N, et al. Long-term follow-up analysis of 100 patients with splenic marginal zone lymphoma treated with splenectomy as first-line treatment. Leuk Lymphoma. 2014;55 (8):1854-1860. doi:10.3109/10428194.2013.861067
Journal of Blood Medicine

\section{Publish your work in this journal}

The Journal of Blood Medicine is an international, peer-reviewed, open access, online journal publishing laboratory, experimental and clinical aspects of all aspect pertaining to blood based medicine including but not limited to: Transfusion Medicine; Blood collection, Donor issues, Transmittable diseases, and Blood banking logistics; Immunohematology; Artificial and alternative blood based

\section{Dovepress}

therapeutics; Hematology; Biotechnology/nanotechnology of blood related medicine; Legal aspects of blood medicine; Historical perspectives. The manuscript management system is completely online and includes a very quick and fair peer-review system. Visit http://www.dovepress.com/testimonials.php to read real quotes from published authors. 